\title{
Responsabilidad Social Corporativa: análisis del caso de Marruecos
}

\author{
Anouar BAKKALI
}

DOI: $10.1387 /$ reves. 15263

Fecha de entrada: 22/09/2014

Fecha de aceptación: 15/03/2015

\begin{abstract}
Sumario: 1. Introducción. 2. Responsabilidad Social Corporativa: marco general. 3. Responsabilidad Social Corporativa en países en vía de desarrollo. 4. RSC y las empresas en Marruecos. Principales tendencias y cauces de su aplicación. 5. Nivel de sensibilización de la RSC en las empresas marroquíes. 6. Compromisos de Marruecos en materia de RSC. 7. Reflexiones y conclusiones finales. 8. Referencias.
\end{abstract}

\section{Resumen:}

En este trabajo se pretende realizar una aproximación a la situación actual de la Responsabilidad Social Corporativa (RSC) en Marruecos, con el objetivo de aportar al conocimiento de un tema en el que existen pocos antecedentes de investigación académica. En primer lugar se analiza la situación económica, el código de trabajo y la situación medioambiental del país. En segundo lugar, se recogen los datos de un estudio realizado para determinar el grado del conocimiento de la RSC en las PYMES marroquís. Por último, se recogen los diferentes compromisos, internacionales, regionales y locales, en los cuales participa Marruecos para seguir avanzando en materia de política social. Como conclusión más relevante destacar que pese a que la participación del estado y el sector privado está en pleno crecimiento, en la realidad esta participación queda muy limitada debido al reducido número de las políticas sociales y medioambientales actuales puestas en marcha por los poderes públicos y la casi ausencia de la participación de las micro y pequeñas empresas en el desarrollo de la RSC en el país.

\section{Palabras clave:}

Marruecos, Responsabilidad social corporativa, medio ambiente, compromisos RSC. 


\begin{abstract}
:
The aim of this study is to to make an approach to the current situation of Corporate Social Responsibility (CSR) in Morocco, in order to contribute to the knowledge of a topic in which there are no many academic research done. First, it studies the Moroccan economy, the labor code, and the environmental situation of the country. Second, it provides data from a study to determine the degree of knowledge of CSR in the Moroccan SMEs. Finally, the various commitments, international, regional and local, in which Morocco participates to further advance of social policy are detailed. The most important conclusion noted that although the participation of government and the private sector is growing, in reality, this participation is very limited due to the small number of current social and environmental policies implemented by the moroccan government and the very limited participation of micro and small enterprises in the development of CSR in the country.
\end{abstract}

\title{
Key words:
}

Morocco, Corporate social responsibility, environment, CSR commitments.

\section{Claves ECONLIT}

M14, F23, F64

\section{Introducción}

La responsabilidad social corporativa (RSC) es un término que, aplicado al ámbito empresarial, trata de una responsabilidad de carácter ético, entendida como la gestión responsable de las organizaciones empresariales. Abarca aquellas responsabilidades que la empresa asume ante la sociedad o ante sus grupos de interés («stakeholders»), porque lo exige la ley, porque forman parte de su función, o porque la organización lo asume voluntariamente.

Las empresas que ponen en práctica actividades social y ambientalmente responsables como parte de su estrategia de negocios tienen un impacto positivo y sostenible en crecimiento, desarrollo y reducción de la pobreza. Si una empresa pone en práctica estas actividades de una forma coherente puede ayudar a mejorar su acceso a bienes y servicios, empleos de calidad, nuevas oportunidades de actividades económicas que generen autoempleo y pueda contribuir a generar cadenas de valor responsables (Vives y Peinado-Vara, 2006). 
Según Daugareil (2009), la responsabilidad social empresarial es una cuestión al alza. Considerada por unos como parte del nuevo pacto social de nuestra época, o bien de la nueva gobernanza en construcción, tan reclamada en momentos de crisis como los que hoy vivimos, apenas sigue siendo para otros algo más que una moda pasajera.

La Responsabilidad Social Corporativa (RSC) cobra un nuevo sentido tras la crisis mundial por diversas razones. En primer lugar, porque la crisis ha puesto en entredicho la visión clásica del liberalismo económico. La urgencia de las ayudas estatales ha venido a evidenciar el reconocimiento implícito de las repercusiones sociales de la empresa hacia clientes, proveedores y otros afectados y, por tanto, que la responsabilidad moral exigible a la empresa es muy superior a la que algunos habían prescrito (Iborra-Juan, Peris-Suay, 2010). En otras palabras, en tiempos de crisis, las empresas responsables pueden ofrecer soluciones sostenibles a problemas socioeconómicos contribuyendo a la reducción de la pobreza. En este sentido creemos que el potencial de la RSC es aún más relevante y necesario en países en desarrollo como es el caso de Marruecos.

El desarrollo económico y social que ha tenido lugar en Marruecos durante las últimas décadas ha permitido la creación de las infraestructuras básicas para responder a las necesidades socio-económicas de la población. Varios sectores han crecido considerablemente, como el turismo, industria, pesca, agua, vivienda, etc. Esta evolución ha provocado una creciente explotación de los recursos naturales y la degradación del medio ambiente debido a la emisión de gases contaminantes y de vertidos sólidos en ausencia de medidas técnicas y legales que puedan frenar esta degradación.

La RSC es un concepto bastante nuevo a Marruecos, pero que está en plena evolución ya que todas las partes interesadas (gobierno, sector privado, ONG... etc.) son perfectamente consientes de su importancia y su impacto sobre el desarrollo económico y social del país. También cabe destacar que resulta difícil determinar el grado de implantación de la RSC en las empresas de Marruecos, debido fundamentalmente a que no existe un estándar único reconocido que sea capaz de medirlo. Del mismo modo, es muy difícil acceder a fuentes de información fiables.

\section{Responsabilidad Social Corporativa: marco general}

La actividad de cualquier empresa supone un impacto más allá de su propio entorno; éste puede ser positivo o negativo. La empresa se beneficia de los efectos positivos, mejorando su imagen corporativa por ejemplo, 
y tiene la obligación de hacerse responsable y comprometerse a eliminar o compensar los efectos negativos. De la convicción con que la organización asuma su responsabilidad social, surgirá una gestión a la altura de las demandas del momento en lo económico, pero también en lo humano y lo moral.

\subsection{Aproximación al concepto de la responsabilidad social corporativa}

A priori, no resulta fácil consensuar una noción única de la terminología RSC, pero sí se puede admitir como interpretación más generalizada, en la actualidad, aquella comprensiva de su característica económica, social, ética y ambiental. Cuevas (2011) afirma que a la hora actual existe el consenso que se trata de una nueva disciplina formando parte de las ciencias de la Administración.

Para Jiménez (2009), la Responsabilidad Social Corporativa (RSC) se considera, en la actualidad, la filosofía en donde debe enmarcarse el comportamiento empresarial en su conjunto, como estrategia de funcionamiento y supervivencia. Se encuentran diferentes consideraciones y definiciones de lo que se entiende por RSC y, por lo tanto, no existe una única definición ni consideración totalmente aceptada a nivel internacional, lo cual permite múltiples aproximaciones conceptuales, desde diversas ópticas, en base a su criterios generales, objetivos que se pueden alcanzar y elementos a considerar.

Para Porter y Kramer (2011), la Responsabilidad Social Corporativa (RSC) es una forma de gestión de los negocios que en los últimos años está atrayendo una gran atención por parte de los académicos debido al interés por determinar cómo contribuye a la mejora de la sociedad y a la competitividad de las empresas.

La Comisión europea (EUROPEAN COMMISSION, 2011) define la RSC, en su comunicación sobre Responsabilidad Social Corporativa «A renewed EU strategy 2011-14 for CSR», como la responsabilidad de las empresas por sus impactos en la sociedad. Para asumir esta responsabilidad, las compañías deben contar con un proceso para integrar en sus operaciones comerciales y en estrecha colaboración con los stakeholders, los asuntos sociales, relativos al medio ambiente, ética, derechos humanos y preocupaciones de los consumidores, con el objetivo de:

- maximizar la creación de valor compartido (sharedvalue) con los propietarios/accionistas, los demás grupos de interés y la sociedad en general;

—identificar, prevenir y mitigar posibles impactos adversos. 


\subsection{Evolución del concepto de la responsabilidad social corporativa}

En los últimos años ha aumentado significativamente el interés, tanto en el ámbito académico como en el empresarial, por la Responsabilidad Social Corporativa, también llamada Responsabilidad Social Empresarial. Sin embargo, el concepto de RSC tiene una larga historia, cuyo tratamiento en la literatura se remonta a la década de los 50 como otros muchos conceptos en torno a la gestión de empresas.

En la revisión de la literatura sobre el tratamiento conceptual y empírico de la RSC, se destaca el amplio y profundo trabajo de recopilación realizado por Carroll (1979), en su artículo «A Three-Dimensional Conceptual Model of Corporate Performance», recoge de manera exhaustiva la evolución del concepto RSC desde la década de los 50, a raíz de la publicación del libro de Howard Bowen en 1953 «Social Responsibilities of the Businessman», hasta finales de la década de los 70.

El enfoque más destacado en los años 1970 fue el protagonizado por Milton Friedman (Premio Nóbel de Economía en 1976). Friedman (1970) argumentó que los individuos invierten en empresas para obtener beneficios económicos mientras deja para la esfera personal el resto de los objetivos. Aunque podrían terminar afectando a otros, ya que para evitar la reducción de beneficios los directivos podrían reducir el salario de los trabajadores, el precio pagado a los proveedores, o subir el precio del producto o servicio vendido a los consumidores. De un modo u otro se gastan el dinero de otros.

Para este destacado economista, lo responsable desde la empresa era preocuparse del retorno para el propietario (accionista en el caso de las sociedades anónimas) y que, el destinar recursos fuera de este objetivo era irresponsable por parte de los administradores de la misma. El único objetivo de la empresa es el beneficio económico, aunque también reconocía que los directivos deben actuar de conformidad con las reglas básicas de la sociedad: aquellas incorporadas en la legislación y en los usos éticos. Cabe destacar que pasando los años, Friedman ha mantenido las mismas ideas (Friedman 2008).

La postura de Friedman ha sido la seguida por las empresas hasta los mediados de los ańos ochenta. En 1984 aparece el concepto de stakeholder (grupo de interés), como complemento al shareholder como única parte interesada en la organización. Según Fernández y Bajo (2012), Freeman en 1984, define el concepto de "stakeholder" como cualquier individuo o grupo de interés que, de alguna manera - explícita o implícita; voluntaria o involuntaria - tenga alguna apuesta hecha - to stake, poner algo en juego- en la marcha de la empresa; y que si, por un lado, se ven condicionados, de manera más o menos directa, por la actividad de 
aquélla, pueden, a su vez, condicionarla. En resumidas cuentas, cualquier grupo o individuo que puede afectar o ser afectado por la consecución de los objetivos empresariales. Para Elósegui (2010), la teoría de los stakeholders (grupos de intereses) (Freeman, 1984: 31) nace motivada por la idea de que el fin de la empresa no es únicamente obtener beneficios económicos para los propietarios y accionistas, sino generar beneficio social haciéndolo extensivo a otros grupos que apoyaban o garantizaban la existencia de la empresa, mediante el trabajo, la compra de sus productos, etc.

El interés que ha despertado este concepto está vinculado principalmente al modelo de empresa plural y dinámica que propone Navarro (2008). Este autor afirma que desde sus primeras definiciones este enfoque ha sido utilizado para describir las relaciones de la empresa con su entorno, pero también para generar estrategias o guías de acción para la empresa moderna, dando respuesta a su RSC concreta.

Desde 1990 hasta ahora es muy abundante la literatura en torno a la Responsabilidad Social. Para Cuevas (2011), durante la década de 1990 hasta la actualidad se propaga — bajo el impulso de las instituciones de Naciones Unidas, ONU, PNUD y PNUE - la doctrina del Desarrollo Sustentable (DS) cuya adaptación por las empresas deviene RSE.

Así pues, se puede decir que actualmente las empresas están consideradas como agentes fundamentales para el desarrollo de la sociedad, aunque, se les exige, además de los resultados económicos, otros objetivos sociales, medioambientales y laborales. Por ende, la Responsabilidad Social Corporativa debe formar parte de la definición de la misión y los objetivos de la empresa, representando una oportunidad estratégica para que la misma desarrolle una gestión que considere las necesidades demandadas por los diferentes grupos de interés. En la práctica real, cabe calificar a una empresa como socialmente responsable si adecuadamente ha integrado en sus políticas, objetivos, funciones y actuaciones, y de forma voluntaria (esto es, además de los mínimos exigidos por la legislación vigente), un cuadro representativo de conductas y prácticas que contribuyan de forma eficaz a mejorar el entorno económico, social y medioambiental. Asumiendo, para ello, compromisos concretos, públicamente expresados, y con respecto a todos los (sus) grupos de interés.

\section{Responsabilidad Social Corporativa en países en vía de desarrollo}

El proceso actual de globalización está produciendo desequilibrios, tanto entre los países como dentro de ellos. Hay varios países y per- 
sonas que han visto empeorar sus condiciones de vida considerablemente como consecuencia de ello. Actualmente, la tendencia mundial busca principalmente mejorar la competitividad de las empresas, hacerlas sostenibles y rentables en el tiempo y contribuir con modelos de desarrollo y acciones relacionadas con la RSC. Sin embargo, no existe la misma aceptación ni comprensión del significado de la RSC en todo el planeta. Paradójicamente, los países con mayor índice de pobreza y desigualdad económica, parecieran más renuentes a la adopción de la referida filosofía.

Para Ferre et al. (2011), el interés por la RSC es creciente en el ámbito internacional y en especial en los países en vía de desarrollo. En este sentido las acciones de las empresas encuadradas en el concepto de RSC son visualizadas como:

— un medio para fortalecer las políticas económicas que permitan el desarrollo sustentable,

- mecanismos de fortalecimiento de las estrategias de competitividad,

- posicionamiento de las exportaciones en el mercado internacional,

— una forma de atraer inversores extranjeros,

— un nuevo enfoque para luchar contra la pobreza.

Según El Malki (2010), resulta interesante destacar que existen grandes diferencias en lo que se refiere a la definición de los criterios de RSC entre los países del norte y los del sur. En muchos países del sur, las actividades de la RSC no tienen prácticamente ninguna relación con el negocio principal de la organización. La mayoría de estas actividades están relacionadas con la función social de la empresa en la comunidad. Así que hay una gran confusión en el concepto de RSC. El autor explica en su trabajo que otra diferencia importante es la existencia y la calidad de las instituciones entre el Norte y el Sur. Las empresas de los países nórdicos tienen estructuras gubernamentales fuertes que son capaces de actuar como reguladores. También existe una sociedad civil bien desarrollada capaz de seguir de cerca las actividades de las empresas a nivel nacional e internacional. En el Sur, sin embargo, estas iniciativas tienden a ser menores. De hecho, la sociedad civil es, en general, poco desarrollada y en la mayoría de los casos, los gobiernos no tienen la suficiente capacidad para hacer frente a las actividades de las empresas.

Cabe señalar que como el objetivo de nuestro estudio es estudiar el desarrollo de la RSC en un país emergente perteneciente al continente africano y al mundo arabo-musulmán, hemos creído conveniente hacer un especial énfasis en revisar la literatura existente en estas dos zonas: África subsahariana y el mundo árabe (Magreb y oriente medio). 


\section{África subsahariana}

La realidad Africana es dramática. Según los datos del fondo monetario internacional (FMI, 2014) casi la mitad de la población (45\%) vive con menos de un 1,25 dólar al día. Cabe señalar que el fondo monetario internacional, en colaboración con instituciones nacionales, otros organismos de desarrollo y la sociedad civil, realiza periódicamente tareas de análisis para evaluar el alcance y las causas de la pobreza y la desigualdad, examinar el impacto del crecimiento y las políticas públicas, y revisar los datos de encuestas de hogares y los métodos de medición.

Según el Comité Económico y Social Europeo (2014), en la Declaración Final de la Red de Agentes Económicos y Sociales UE-AFRICA sobre los sistemas de protección social, se han pedido las siguientes acciones:

1. tener en cuenta las particularidades de la economía informal, muy extendida en África, que se caracteriza por la ausencia de protección jurídica y social, ingresos escasos e irregulares, dificultades para acceder a los créditos, empleos precarios, incumplimiento de las normas de seguridad y sanitarias, una escasa solidaridad social hacia las personas con discapacidad y las personas mayores, servicios sociales poco adaptados e instituciones del mercado laboral poco adecuadas;

2. recomendar la integración progresiva de la economía informal en los sectores públicos y privados. Esta integración debe intentar transformar a las empresas informales en empresas viables e integradas en la economía formal. Debe ir acompañada de un refuerzo de los agentes sociales y de un diálogo social y requiere, en particular, la simplificación de los procedimientos administrativos para crear empresas, la promoción de las normas internacionales del trabajo y la facilitación del acceso al crédito;

3. recuerdan que en el continente africano la economía social forma parte integrante de las estructuras tradicionales de solidaridad, de empresas colectivas y comunitarias, que a menudo se transforman en cooperativas. Piden a las autoridades europeas y africanas que reconozcan la contribución de los agentes de la economía social, incluidas las cooperativas, a la erradicación de la pobreza, al desarrollo local sostenible y al fomento del trabajo decente, y les instan a que incluyan la economía social, incluidas las cooperativas, en el Plan de Acción UE-África 2014-2017. Estos datos, sin duda son muy alarmantes, sin embargo África conoce los últimos ańos un desarrollo económico esperanzador. 
Según Delacampagne (2013), desde el inicio del siglo xxi, numerosos países africanos se encuentran entre los de mayor crecimiento del mundo. En 2012, 6 de las 10 economías con mayor tasa de crecimiento mundial son africanas. Angola, Chad, Guinea Ecuatorial, Etiopía, Ghana, Liberia, Libia, Mozambique, Ruanda y Sierra Leona han crecido a un ritmo medio de entre el 7 y el 11 por 100 en el período 2004-2012.

En lo que se refiere a las cuestiones relacionadas con la responsabilidad social corporativa, se puede decir que la lógica de la RSC es un concepto muy poco conocido y compartido en las empresas de origen africano. Sin embargo, las prácticas de la RSC están creciendo cada vez más debido al fenómeno de las deslocalización de las grandes empresas y las empresas transnacionales que se instalan, en la mayoría de los casos, en las regiones donde se producen las materias primas y explotan de forma incorrecta los recursos naturales de dichas regiones. Las iniciativas en materia de RSC llevadas a cabo por estas empresas son apenas visibles o en el mejor de los casos aisladas y excepcionales. Las pocas acciones llevadas a cabo son generalmente el resultado de las obligaciones a las que estas grandes empresas son sujetas según la legislación vigente en sus país de origen (Europa, EE.UU., Japón..., etc). En este sentido podemos mencionar el documento sobre la Nueva Alianza para el Desarrollo de África, que, fomentando la inversión extranjera directa, exige al mismo tiempo una redefinición de las reglas de esta asociación para que ésta sea mutuamente benéfica (Unión Africana, 2001).

\section{Magreb y Oriente medio}

Aunque algunos países y empresas en el mundo árabe están más avanzados que los demás, la RSC, de manera general, sigue siendo considerada como una actividad segundaria para las empresas y no forma parte de un proceso interno que se integre en las operaciones centrales, la estrategia y la planificación a largo plazo. La RSC normalmente ha sido introducida por las multinacionales, y se transmite a través de filiales en la región. Cabe destacar que las prioridades en materia de la RSC pueden ser totalmente diferentes respecto a los países occidentales o de otras regiones el mundo.

Según Ararat (2006), el papel de la mujer exige una atención especial. Una sociedad activa no puede ser posible sin la participación de las mujeres. El apoyo a la educación de las mujeres ha sido considerado como uno de los temas preferidos en la región.

Otra particularidad de esta región es la escasez del agua potable. En un estudio llevado a cabo por Ruiz de Gauna (2012), se puede concluir 
que la escasez de agua y sus malas condiciones de salubridad son una de las múltiples causas de la pobreza. Si bien es cierto que los países de Oriente Medio y Norte de África (MENA), comparativamente con otras regiones en desarrollo, tienen unos niveles de pobreza bajos, hay diferencias entre los países que conforman la región. En zonas fundamentalmente rurales tienen serias dificultades para acceder al agua potable, debido a la inexistencia de sistemas de abastecimiento. No obstante, no se debe pensar que la falta de acceso se debe, únicamente, a la falta de ingresos, sino que los aspectos culturales, políticos, medioambientales, institucionales o económicos afectan de forma considerable, como, por ejemplo, la legislación sobre los derechos de propiedad de la tierra que, en múltiples casos, impide la instalación de plantas de abastecimiento de agua potable. En cuanto a los efectos del cambio climático, los recursos naturales e hídricos se van agotando debido al aumento de la temperatura del planeta, provocando desempleo y migraciones campo-ciudad.

\section{RSC y las empresas en Marruecos. Principales tendencias y cauces de su aplicación}

El punto de partida ha de ser la constatación del retraso que presenta Marruecos, bastante acusado, en relación con los países europeos. La ausencia de apoyos por parte de los poderes públicos, la escasez de organizaciones de referencia, creíbles, sólidas e independientes que guíen el desarrollo del concepto, y el escaso desarrollo de la filosofía de inversión RSC, entre otras causas, contribuyen a frenar el desarrollo del enfoque RSC en Marruecos. La existencia de referente adecuado de mercado en el ámbito RSC permitiría fijar la atención de las empresas en la dirección correcta y ayudaría a combatir la banalización del concepto producida por una previsible proliferación de enfoques y, presumiblemente, permitiría mantener el concepto a la par con los avances en gestión empresarial, materia dinámica por excelencia.

En este capítulo se pretende ofrecer un diagnóstico de la actual situación de la RSC en Marruecos, esto es, lo que está sucediendo en el ámbito institucional y empresarial.

Este análisis es necesario para ver cómo las políticas públicas y privadas pueden incentivar el desarrollo del enfoque RSC en Marruecos. Cabría, pues, dividir el análisis de la actual situación de la RSC en Marruecos enfocándonos en tres ámbitos: Contexto económico, código de trabajo y medio ambiente. 


\subsection{Contexto económico}

La economía marroquí se caracteriza por la consolidación de los principales indicadores económicos a pesar de las dificultades que pesaron sobre su resultado y sus equilibrios macroeconómicos últimamente. En los últimos años, la economía marroquí se ha caracterizado por una estabilidad macroeconómica unida a una baja inflación y a un crecimiento económico en alza. Pero, con la baja de la demanda europea, su principal mercado, y la sequía que ha afectado a la producción de cereales, el crecimiento económico del país se ha ralentizado en 2012. En 2013, el crecimiento económico ha conocido un repunte (4,54\%). La economía se ha visto beneficiada por una buena temporada agrícola y una demanda interna creciente de 5\%. Cabe destacar que Marruecos se ha dirigido hacia los países del Golfo para atraer inversiones ya que se vio afectado duramente por la crisis de la zona euro, el primer socio comercial del país. Sin embargo, en marzo de 2013, Marruecos inició negociaciones para aumentar su integración económica con la UE. El cuadro1 resume los principales indicadores económicos de Marruecos en el periodo (2010-2014).

\section{Cuadro 1}

Indicadores económicos en Marruecos (periodo 2010-2014)

\begin{tabular}{|c|c|c|c|c|c|}
\hline Indicadores de crecimiento & 2010 & 2011 & 2012 & 2013 & 2014 \\
\hline PIB (miles de millones de USD) & 90.771 & 99.211 & 95.981 & 105.101 & 114.731 \\
\hline $\begin{array}{l}\text { PIB (crecimiento anual en } \% \text {, } \\
\text { precio constante) }\end{array}$ & 3.643 & 4.986 & 2.695 & 4.542 & 3.908 \\
\hline PIB per cápita (USD) & 2,849 & 3,082 & 2,951 & 3,199 & 3,457 \\
\hline $\begin{array}{l}\text { Endeudamiento del Estado (en } \\
\% \text { del PIB) }\end{array}$ & 51.298 & 54.385 & 60.154 & 61.911 & 62.70 \\
\hline Tasa de inflación(\%) & 0.994 & 0.907 & 1.287 & 1.881 & 2.500 \\
\hline $\begin{array}{l}\text { Tasa de paro ( } \% \text { de la población } \\
\text { activa) }\end{array}$ & 9.063 & 8.912 & 8.988 & 9.235 & 9.135 \\
\hline $\begin{array}{l}\text { Balanza de transacciones corrientes } \\
\text { (miles de millones de USD) }\end{array}$ & -3.749 & -7.985 & -9.346 & -7.815 & -7.595 \\
\hline $\begin{array}{l}\text { Balanza de transacciones } \\
\text { corrientes (en \% del PIB) }\end{array}$ & 4.130 & -8.049 & -9.738 & -7.435 & -6.620 \\
\hline
\end{tabular}

Fuente: Elaboración propia a partir de: International Monetary Fund (2014). 


\subsection{Código de trabajo}

El código de trabajo marroquí se caracteriza por su conformidad con los principios básicos establecidos por la Constitución así como por las normas institucionales previstas según los convenios de las Naciones Unidas y de sus organizaciones especializadas y relacionadas con el ámbito laboral.

Los derechos protegidos incluyen:

- la libertad sindical y la adopción efectiva del derecho de organización y de negociación colectiva;

- la prohibición de todas formas de trabajo bajo coacción;

- la eliminación efectiva del trabajo infantil;

- la prohibición de la discriminación en el empleo;

— la igualdad de los salarios.

En el cuadro siguiente se presentan las principales ventajas y desventajas del código en vigor:

\section{Cuadro 2}

Ventajas y desventajas del código de trabajo marroquí en vigor

Ventajas

1. Salud en el trabajo: El seguro de accidentes de trabajo y enfermedades profesionales es obligatorio.

2. Despido: Si el empresario reconoce la improcedencia de su decisión, debe abonar al trabajador la indemnización de 45 días por año trabajado.

3. Salarios: Subida del salario mínimo interprofesional de $10 \%$ en dos ańos a partir del mes de mayo del 2014.

4. Seguridad y medio ambiente: Marruecos aprueba el convenio C187-Convenio sobre el marco promocional para la seguridad y salud en el trabajo. Lo ha hecho en el BO n. ${ }^{\circ}$ 6.166, del 4 de julio del 2013, bajo la ley 16-12.
Desventajas

1. Código de Trabajo incompleto: Ciertas categorías de trabajadores quedan fuera de cualquier protección legal :(empleados de hogar, empleados de la artesanía tradicional, artistas..., etc.).

2. Otras categorías de trabajadores siguen rigiéndose por un código de ley independiente: Funcionarios y agentes del gobierno, instituciones públicas , periodistas..., etc.).

3. No integra las disposiciones del Convenio 135 de la OIT sobre la protección de los representantes de los trabajadores pese al compromiso formal del Gobierno de ratificar el Convenio.

4. Horas de trabajo: 44 horas semanales.

Fuente: Elaboración propia. 


\subsection{Medio ambiente}

Uno del los rasgos característicos de nuestra era es la preocupación por el medio ambiente y Marruecos no ha sido una excepción, si bien es cierto que las condiciones medioambientales del país no son las mejores, en los últimos años, parece haber tomado conciencia de su importancia y son numerosas las iniciativas que se están llevando a cabo al respecto. Las instituciones perezosas en su papel regulador y educador de la conciencia medioambiental convertían a Marruecos en un país que vivía de espaldas al medioambiente.

En el año 2010 se realizó un estudio medioambiental denominado (Rapport de Diagnostic de l'Etat de l'Environnement au Maroc) conocido como RDEEM, cuyo objetivo principal consistía en analizar y diagnosticar la situación medioambiental del país para así poder emprender las acciones necesarias para su mejora. De este análisis salieron varias conclusiones sobre las causas del deterioro medioambiental del país. En el medio urbano se observó que las condiciones de las vías de emisión rondaban la insalubridad, entre otras cosas por las deficiencias en la recogida de residuos domésticos, la contaminación de las aguas (debido a la escaza aplicación de normativas en cuanto a emisiones de gases y vertidos no controlados). Respecto a los residuos, las actividades socio-económicas, junto con el crecimiento demográfico y los cambios en el modo de consumo generan una producción significativa de residuos sólidos. La producción de residuos sólidos en la actualidad se sitúa en cerca de 18.000 toneladas/día, con un promedio de $0,75 \mathrm{~kg} / \mathrm{hab} /$ día $(0,3 \mathrm{~kg} / \mathrm{habi}-$ tante/día en las zonas rurales y $1,2 \mathrm{~kg} / \mathrm{hab} /$ día en las zonas urbanas y suburbanas).

El agua se ve amenazada por todas las formas de contaminación. El fracaso en términos de tratamiento de aguas residuales y de las aguas residuales es una de las principales causas del deterioro de la calidad de las aguas superficiales y subterráneas. De hecho, más del $90 \%$ de las aguas residuales, $750 \mathrm{~mm}^{3} /$ ańo, es vertido sin tratamiento. Del mismo modo, gran parte de los residuos no se deposita en los vertederos y que puede acabar en zonas donde los recursos hídricos son vulnerables.

En cuanto a la calidad del aire, la polución proviene de la emisión de gases tóxicos como el óxido de nitrógeno (NOx), con 35.000 t/año, el dióxido de azufre $\left(\mathrm{SO}_{2}\right)$, con 21.000 t/año de dióxido de carbono $\left(\mathrm{CO}_{2}\right)$ con 7.000.000 t/año y las partículas en suspensión con 5.000 t/año. Se estima que el 50 a $60 \%$ de esta polución es derivada de un obsoleto parque automovilístico junto a la mala calidad de los carburantes.

Por su parte las condiciones del medio rural tampoco eran muy esperanzadoras ya que a la mala gestión de los recursos naturales se une la dis- 
minución del capital destinado a tal fin, lo que acrecentaba el éxodo a la ciudad.

Además de las causas anteriormente mencionadas conviene recordar que Marruecos es un país con unas condiciones climáticas no demasiado favorables (periodos de sequia prolongados, zonas desérticas, etc.). La erosión hídrica que afecta a más de 10 millones de hectáreas, se manifiesta de manera significativa en las montańas del Rif donde la degradación a me-

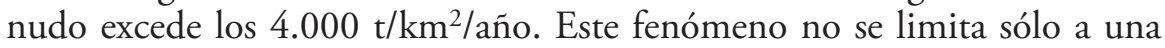
gran pérdida de suelo, sino que también causa la sedimentación de las con una reducción anual de unos 60 millones de $\mathrm{m}^{3}$, lo que corresponde a una pérdida media de capacidad de irrigación de aproximadamente 6.000 ha/ año aproximadamente.

Afortunadamente, a la vista de los resultados obtenidos por el RDEEM son numerosas las iniciativas que se están desarrollando para mejorar la situación medioambiental y lo que es más importante para concienciar la importancia del mismo. Respecto al tratamiento del agua, el Office Nacional de l'Eau Potable (ONEP) ha diseñado más de cien actuaciones basadas en tres ejes: la consolidación de infraestructuras, la generación de acceso al agua potable (especialmente en el medio rural) y el tratamiento y saneamiento de las aguas.

Importantes avances en términos de movilización de recursos para el agua ha marcado este sector permitiendo desarrollar múltiples subsectores (irrigación agua potable, saneamiento de hidroelectricidad) así como paliar el riesgo de inundaciones. Además debido a los cambios climáticos una nueva política del agua se hace necesaria para definir las prioridades sectoriales. Por esto se ha adoptado una nueva estrategia nacional del sector para el periodo 2009-2030, fijando como prioridades: el ahorro del agua, la mejora del acceso al agua potable y la gestión de la demanda centrada en la calidad de los recursos.

En cuanto al tratamiento de los desechos, el gobierno ha lanzado un programa nacional de gestión de desechos del hogar (PNGDMA) que con un amplio presupuesto pretende dar un giro a la situación en los próximos 15 años. En lo que respecta a los desechos industriales se ha creado un fondo de descontaminación industrial (FODEP) que creará instalaciones dedicadas al tratamiento y eliminación de residuos industriales.

La descontaminación atmosférica se pretende realizarse dando impulso a las energías renovables, ya comentadas en el apartado de la energía.

Otras acciones puestas en marcha por Marruecos para cuidar y proteger el medio ambiente son: 
— firma de una serie de tratados y acuerdos internacionales. Adhesión al Protocolo de Kyoto en 2002,

— «charte nationale de l'environnement et du développement durable» 2009. Esta Carta establece, en primer lugar, principios empezando por el derecho de cada ciudadano a vivir en un medio ambiente sano y la obligación recíproca de proteger este entorno,

- lanzamiento de un programa Solar a principios de 2010, cuyo coste se estima en 9 MM USD,

— puesta en marcha de un Plan de desarrollo de la energía eólica en junio de 2010, cuyo costo se estima en 3 MM USD.

Otro aspecto importante a tratar sería la evolución del número de empresas certificadas según la norma ISO 14001.Para Jiménez (2009), la ISO 14001 se puede considerar como un indicador de la aceptación y compromiso, por parte de la organización, de la protección del medio ambiente, dentro del comportamiento socialmente responsable de las organizaciones. La aportación que proporciona la aceptación de esta norma para aquellas empresas socialmente responsables se puede resumir en los siguientes puntos:

- Autoevaluación inicial de Gestión ambiental.

- Compromiso y política. Creación de la cultura medioambiental.

- Planificación de la política ambiental, para lo cual necesita:

- Identificación y registro de los aspectos medioambientales y evaluación de los impactos ambientales.

- Requisitos legales.

- Criterio de comportamiento interno.

- Establecer objetivos y metas ambientales.

- Desarrollo de un programa de gestión ambiental.

— Implementación y desarrollo de las capacidades y mecanismos de la política, objetivos y metas ambientales.

— Medición y evaluación para un seguimiento de la política y realización de un feed-back de la misma.

— Revisión, mejoramiento y comunicación para informar a las partes involucradas de los logros ambientales obtenidos.

En la figura 1 se puede apreciar que la evolución ha sido positiva hasta el año 2010 y luego a partir del año 2011, el número de empresas certificadas ha bajado para volver a subir en el año 2013. 


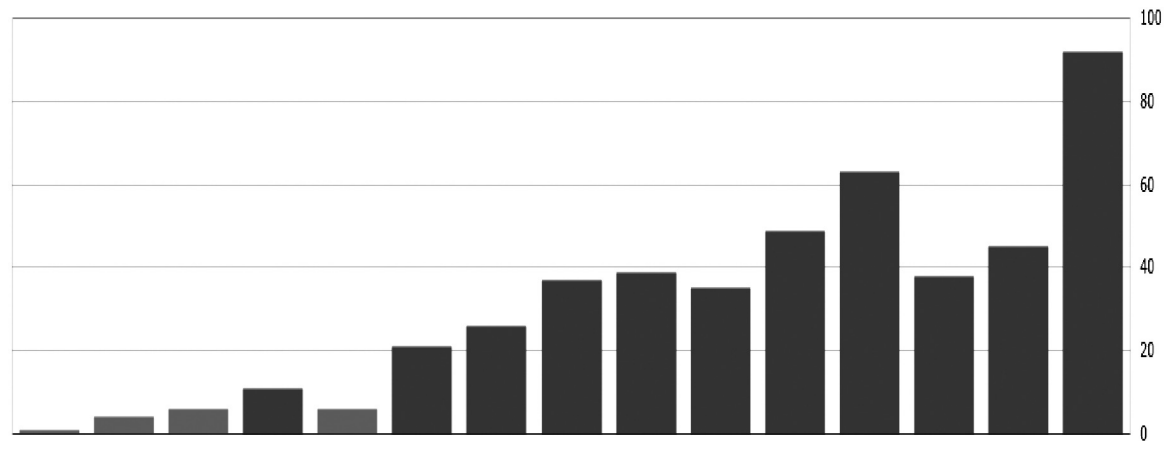

$\begin{array}{lllllllllllllll}1999 & 2000 & 2001 & 2002 & 2003 & 2004 & 2005 & 2006 & 2007 & 2008 & 2009 & 2010 & 2011 & 2012 & 2013\end{array}$

Fuente: ISO (2014).

\section{Figura 1}

Evolución de la certificación ISO 14001 en Marruecos (periodo 1999-2013)

La siguiente figura nos muestra una comparación, según el número de empresas certificadas, entre diferentes países del norte de África y Europa. Se puede apreciar que el número de empresas certificadas en Marruecos sigue siendo inferior respecto a los países de su entorno.

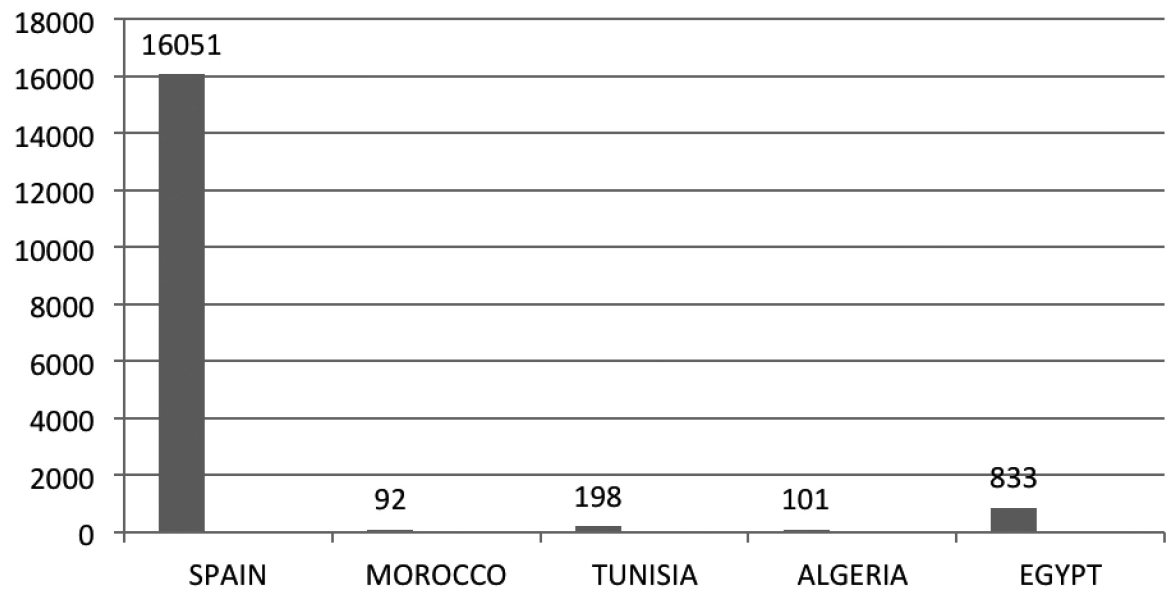

Fuente: Elaboración propia a partir de ISO (2014).

Figura 2

Comparación del número de empresas certificadas ISO 14001 con países de su entorno 


\section{Nivel de sensibilización de la RSC en las empresas marroquíes}

El este epígrafe se va a describir el comportamiento de las empresas marroquíes y la opinión de sus dirigentes en relación a la RSC. Para ello se utilizaron datos de la encuesta sobre RSC realizada a las pequeńas y medianas empresas de la región de Fes Boulemane, la cual fue presentada en el coloquio internacional celebrado en Canadá en 2009 sobre el tema de la vulnerabilidad de las PYMES en un mundo globalizado "La vulnérabilité des TPE et des PME dans un environnement mondialisé». Cabe destacar que las PYMES representan una parte muy importante del tejido económico marroquí, con más del $95 \%$ de las empresas. Los poderes públicos marroquíes, conscientes de la importancia socio-económica de las PYME, han realizado esfuerzos considerables en los últimos ańos para mejorar su situación. Pero un esfuerzo adicional resulta imprescindible para lograr apoyar las PYMES durante todo su ciclo de vida, y permitirle así alcanzar la competitividad suficiente para evolucionar en un mercado global.

Según los autores de este estudio, M’hamdi y Trid (2009), del análisis se destaca que más de la mitad de los dirigentes dice haber escuchado hablar de RSC. Por otra parte, se encuentra que se le asigna un importante rol respecto a la mejoría de las relaciones con los clientes y proveedores. Por último, se destaca que más de la mitad de los dirigentes no cree en la existencia de una cierta correlación entre las acciones de RSC implementadas por las empresas y los resultados económicos. Este último resultado ha sido confirmado por un estudio llevado a cabo por Boutti (2009). El autor señala que los dirigentes de las empresas marroquíes no perciben la RSC como una prioridad o como un factor determinante para alcanzar buenos resultados económicos.

A continuación se presentan los principales resultados de este estudio:

$-62,9 \%$ de los dirigentes conocen el término RSC,

$-70,4 \%$ de los dirigentes no conocen las instituciones que ayudan a poner en práctica las iniciativas de RSC,

$-100 \%$ de los dirigentes perciben la RSC como un activo,

$-85,7 \%$ de los dirigentes consideran como beneficios o ganancias derivadas de las acciones de la RSC, la fidelidad de los consumidores y clientes,

- $80 \%$ de los dirigentes consideran como beneficios o ganancias derivadas de las acciones de la RSC, la mejora de las relaciones con proveedores y subcontratistas, 
- $57,1 \%$ de los dirigentes consideran como beneficios o ganancias derivadas de las acciones de la RSC, las buenas relaciones con el entorno local,

- $51,4 \%$ de los dirigentes consideran como beneficios o ganancias derivadas de las acciones de la RSC, la mejora de las relaciones con los interlocutores sociales,

- 42,9\% de los dirigentes consideran como beneficios o ganancias derivadas de las acciones de la RSC, la mejora de los resultados económicos.

\section{Compromisos de Marruecos en materia de RSC}

\subsection{Compromisos internacionales}

Las empresas de Marruecos que están adheridas a entidades internacionales que traten temas relacionados con la RSC tienen el compromiso de trabajar en pro de la implementación de los principios exigidos por dichas entidades. En ocasiones, las empresas, pueden no lograr ubicar el enfoque correspondiente para el proceso de implementación. Por lo que es importante entender que este proceso es de largo plazo e implica una mejora continua en el desempeño.

A continuación se presenta el grado de participación que tienen las empresas de Marruecos en las entidades internacionales más importantes en materia de RSC.

\subsubsection{Organización PARA la CoOperación y Desarrollo ECONÓMICOS (OCDE)}

Fundada en 1961, la Organización para la Cooperación y el Desarrollo Económicos (OCDE) agrupa a 34 países miembros y su misión es promover políticas que mejoren el bienestar económico y social de las personas alrededor del mundo. La OCDE ofrece un foro donde los gobiernos puedan trabajar conjuntamente para compartir experiencias y buscar soluciones a los problemas comunes. Trabaja para entender que es lo que conduce al cambio económico, social y ambiental. Mide la productividad y los flujos globales del comercio e inversión. Analiza y compara datos para realizar pronósticos de tendencias. Fija estándares internacionales dentro de un amplio rango de temas de políticas públicas. 
Las Líneas Directrices de la OCDE para Empresas Multinacionales (en adelante, las Directrices) son recomendaciones dirigidas por los gobiernos a las empresas multinacionales. Enuncian principios y normas voluntarias para una conducta empresarial responsable compatible con las legislaciones aplicables. La vocación de las Directrices es garantizar que las actividades de esas empresas se desarrollen en armonía con las políticas públicas, fortalecer la base de confianza mutua entre las empresas y las sociedades en las que desarrollan su actividad, contribuir a mejorar el clima para la inversión extranjera y potenciar la contribución de las empresas multinacionales al desarrollo sostenible (OCDE, 2011).

Las Directrices incluyen los elementos habituales de la definición de Responsabilidad Social Corporativa: desarrollo sostenible, respeto a los derechos humanos, colaboración con la comunidad, formación de los trabajadores, salud y seguridad laboral, buen gobierno corporativo, sistemas de gestión, difusión y promoción de las políticas corporativas, extensión de las exigencias propias a proveedores y subcontratistas, etc. En este sentido, las recomendaciones sobre reporting, son mucho menos ambiciosas que las contenidas en el modelo de Global Reporting Initiative (Lafuente et al, 2003).

A lo largo de los últimos ańos, Marruecos ha establecido una estrecha relación con la OCDE. De hecho, se ha adherido a varios instrumentos, como la Declaración de la OCDE sobre Inversión Internacional y Empresas Multinacionales (2009), la Declaración de Principios Comunes de Propiedad, Integridad y transparencia en el ejercicio de la actividad y finanzas internacionales (2012) y la Convención sobre Asistencia Administrativa mutua en materia Fiscal, en su versión modificada por el Protocolo de enmienda de la Convención (2013). Marruecos ha experimentado un fuerte crecimiento económico en los últimos ańos, gracias a la creciente demanda interna tanto de los consumidores como de los inversores. Es por ello que el país norteafricano aspira a eliminar los obstáculos a la inversión interna y hacer su economía más atractiva para la inversión extranjera adhiriéndose a este compromiso.

Respecto a la Declaración de la OCDE sobre Inversión Internacional y Empresas Multinacionales, Marruecos se ha sumado a otros 41 países en la firma de esta Declaración, en una decisión que le compromete a afianzar un entorno de apertura para los inversores internacionales y fomentar inversiones responsables por las empresas multinacionales como un medio para promover la prosperidad y el crecimiento. Con la firma de esta Declaración, Marruecos se compromete a tratar a los inversionis- 
tas extranjeros en la misma forma que a los inversionistas nacionales y promover una conducta empresarial responsable. Inversores marroquíes en el extranjero recibirán un trato equitativo similar en otros países signatarios. Estos incluyen los 30 países miembros de la OCDE, así como Argentina, Brasil, Chile, Egipto, Estonia, Israel, Letonia, Lituania, Perú, Rumania y Eslovenia.

\subsubsection{El Global Compact}

El Pacto Mundial de Naciones Unidas (Global Compact) es una iniciativa internacional que promueve implementar 10 Principios universalmente aceptados en las áreas de Derechos Humanos, Normas Laborales, Medio Ambiente y Lucha contra la Corrupción en las actividades y la estrategia de negocio de las empresas. Con más 12.000 entidades firmantes en más de 145 países, es la mayor iniciativa voluntaria de responsabilidad social empresarial en el mundo (Global compact, 2014). Respaldado por los CEOs de las empresas que lo componen, el Pacto Mundial es un marco práctico para desarrollar, implantar y divulgar políticas y prácticas de sostenibilidad corporativa, ofreciendo a sus firmantes una amplia gama de recursos y herramientas de gestión para ayudarles a implementar modelos de negocio sostenible. El Pacto Mundial de Naciones Unidas persigue dos objetivos complementarios:

1. Incorporar los 10 Principios en las actividades empresariales de todo el mundo.

2. Canalizar acciones en apoyo de los objetivos más amplios de las Naciones Unidas, incluidos los Objetivos de Desarrollo del Milenio (ODM).

En el marco de «Programa de Desarrollo Sostenible a través del pacto mundial», Marruecos beneficia de la asistencia de Italia para la aplicación de los principios de este compromiso internacional. El siguiente cuadro muestra el listado de las empresas participantes y la figura 3 muestra la evolución de dicha participación a partir del año 2006, fecha en la cual las primeras empresas marroquíes empezaron a formar parte de las entidades firmantes de este compromiso. 


\section{Cuadro 3}

Listado de empresas marroquíes firmantes del pacto mundial

\begin{tabular}{|c|c|c|c|c|}
\hline Name & Type & Sector & Country & $\begin{array}{l}\text { Participant } \\
\text { since }\end{array}$ \\
\hline Maroclear & SME & Financial Service. & Morocco & $2015 / 02 / 02$ \\
\hline Tradgard Maroc & SME & Support Service. & Morocco & $2014 / 11 / 21$ \\
\hline Alpha Guard & SME & Personal Goods & Morocco & $2014 / 10 / 20$ \\
\hline Real Travel Service & SME & Travel \& Leisure. & Morocco & $2014 / 09 / 11$ \\
\hline ATRAL & SME & Industrial Transportation... & Morocco & $2014 / 07 / 28$ \\
\hline ExperFormance & SME & Software \& Coputer services & Morocco & $2014 / 07 / 14$ \\
\hline Moroccan Institute for... & NGO Local & Not Applicable & Morocco & $2013 / 10 / 28$ \\
\hline Amphitrite Palace Beac... & SME & Travel \& Leisure & Morocco & $2013 / 10 / 23$ \\
\hline Les Eaux Minerales d'O... & Company & Beverages & Morocco & $2013 / 04 / 26$ \\
\hline S’Tours Voyages & SME & Travel \& Leisure. & Morocco & $2013 / 03 / 22$ \\
\hline Maroc Telecom & Company & Fixed Line Telecommunication & Morocco & $2012 / 11 / 13$ \\
\hline Association Bebes Du M... & NGO Local & Not Applicable & Morocco & $2011 / 06 / 08$ \\
\hline Junior Chamber Interna... & NGO Global & Not Applicable & Morocco & $2011 / 06 / 01$ \\
\hline COCHEPA & SME & Forestry \& Paper. & Morocco & $2009 / 11 / 16$ \\
\hline Transparency Morocco & NGO Local & Not Applicable & Morocco & $2009 / 11 / 09$ \\
\hline Union Marocaine du Tra... & Labour Local & Not Applicable & Morocco & $2008 / 12 / 03$ \\
\hline Union Generale des Tra... & Labour Local & Not Applicable & Morocco & $2008 / 11 / 19$ \\
\hline Federation des Chambre... & Public Secto... & Not Applicable & Morocco & $2008 / 08 / 01$ \\
\hline Apebi-Federation Mor... & Business Ass... & Not Applicable & Morocco & $2007 / 10 / 15$ \\
\hline Confederation Generale... & Business Ass... & Not Applicable & Morocco & $2006 / 12 / 12$ \\
\hline Reseau Espace de Citoy... & Business Ass... & Not Applicable & Morocco & $2006 / 12 / 06$ \\
\hline ERAMEDIC & SME & Health Care equipments ans services & Morocco & $2006 / 07 / 28$ \\
\hline
\end{tabular}

Fuente: Global compact (2015).

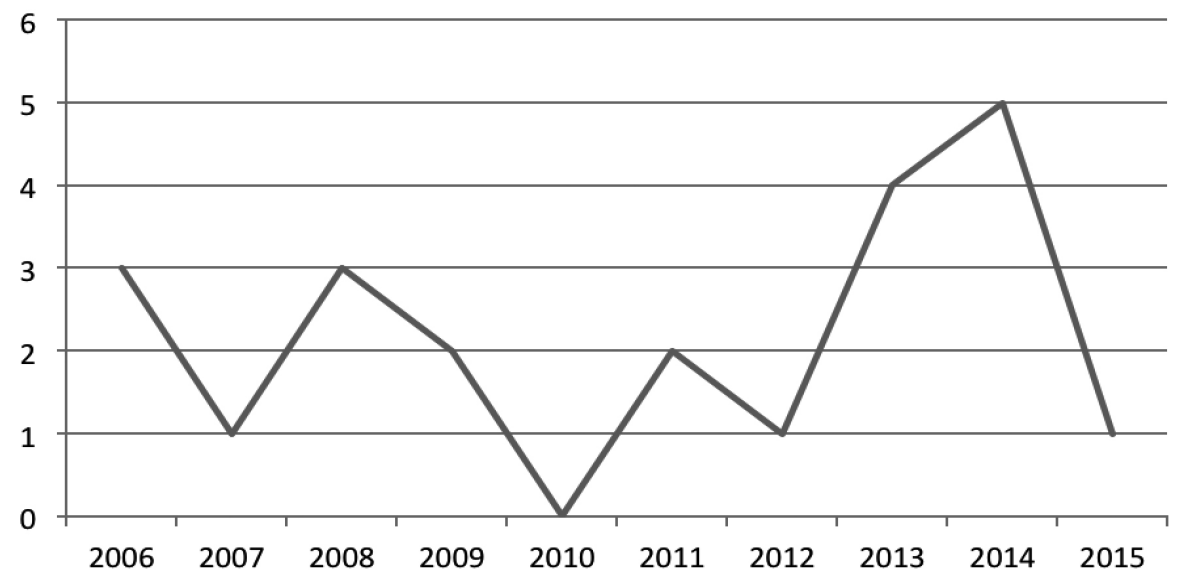

Fuente: Elaboración propia a partir de global compact (2015).

\section{Figura 3}

Evolución de la participación de las empresas marroquíes en global compact 
La siguiente figura nos muestra una comparación, según el número de empresas firmantes del pacto mundial, entre diferentes países del norte de África y Europa. Se puede apreciar que el número de empresas marroquíes sigue siendo inferior respecto a los países de su entorno salvo Argelia.

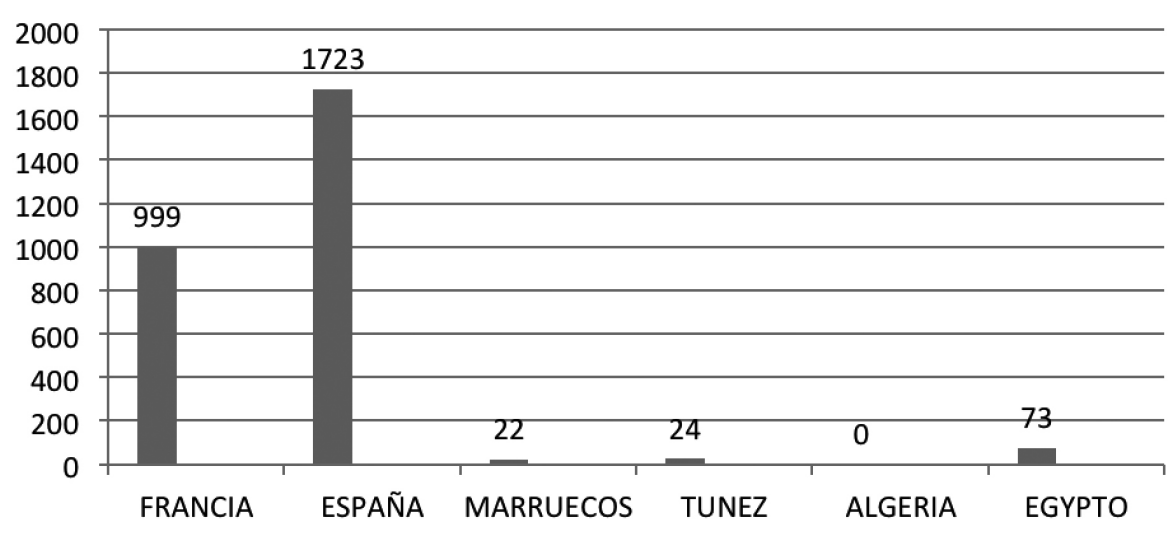

Fuente: Elaboración propia a partir de global compact (2015).

Figura 4

Comparación de la participación de las empresas marroquíes con países de su entorno

\subsubsection{El Global Reporting Initiative}

Global Reporting Initiative (GRI) es una organización sin ánimo de lucro con múltiples grupos de interés. Fue fundada por CERES y el Programa de las Naciones Unidas para el Medio Ambiente (PNUMA) en el año 1997 en Estados Unidos. En el año 2002, GRI trasladó sus oficinas a Ámsterdam, donde actualmente se encuentra su Secretaría. GRI cuenta con oficinas regionales (Focal Points) en Australia, Brasil, China, India y Estados Unidos, y además, cuenta con una red de más de 30.000 personas en todo el mundo (GRI, 2015).

GRI es una organización cuyo fin es impulsar la elaboración de memorias de sostenibilidad en todo tipo de organizaciones y cuya misión es hacer de la elaboración de memorias de sostenibilidad una práctica habitual proporcionando orientación y respaldo a las organizaciones. Una memoria de sostenibilidad expone información acerca del desempeño económico, ambiental, social y de gobierno de una organización. Cada vez son más las empresas que desean hacer sus operaciones más sostenibles, y crear procesos para la elaboración de memorias de sostenibilidad que les permitan medir el desempeño, establecer metas y gestionar los cambios necesarios. Una me- 
moria de sostenibilidad es la plataforma clave para comunicar impactos de sostenibilidad positivos y negativos, y para capturar información que pueda influir en la política de la organización, su estrategia y sus operaciones de manera continua. GRI produce un completo Marco para la elaboración de Memorias de Sostenibilidad, cuyo uso está muy extendido en todo el mundo. El Marco, que incluye la Guía para la elaboración de Memorias, establece los principios e indicadores que las organizaciones pueden utilizar para medir y dar a conocer su desempeño económico, ambiental y social. GRI está comprometido con la mejora continua y el incremento del uso de estas Guías, la cuales se encuentran a disposición del público de manera gratuita.

Respecto a la participación por países, de todas las memorias de sostenibilidad de los cuales GRI tiene constancia, los países africanos son los que menor número de memorias han presentado en el año 2014. En este ámbito cabe resaltar que, en 2009, tres organizaciones marroquíes hicieron uso del marco de GRI para la elaboración de informes anuales RSC (Labaronne y Gana, 2009). Una cifra, que en 2014 había descendido a 0. Así mismo, resulta relevante el hecho de que Marruecos sea el país con un nivel muy bajo de aplicación de las guías GRI.

La siguiente figura nos muestra una comparación, entre diferentes países del norte de África y Europa, según el número de empresas que utilizan la guía GRI. Se puede apreciar que ninguna empresa del Magreb había utilizado la guía GRI en 2014.

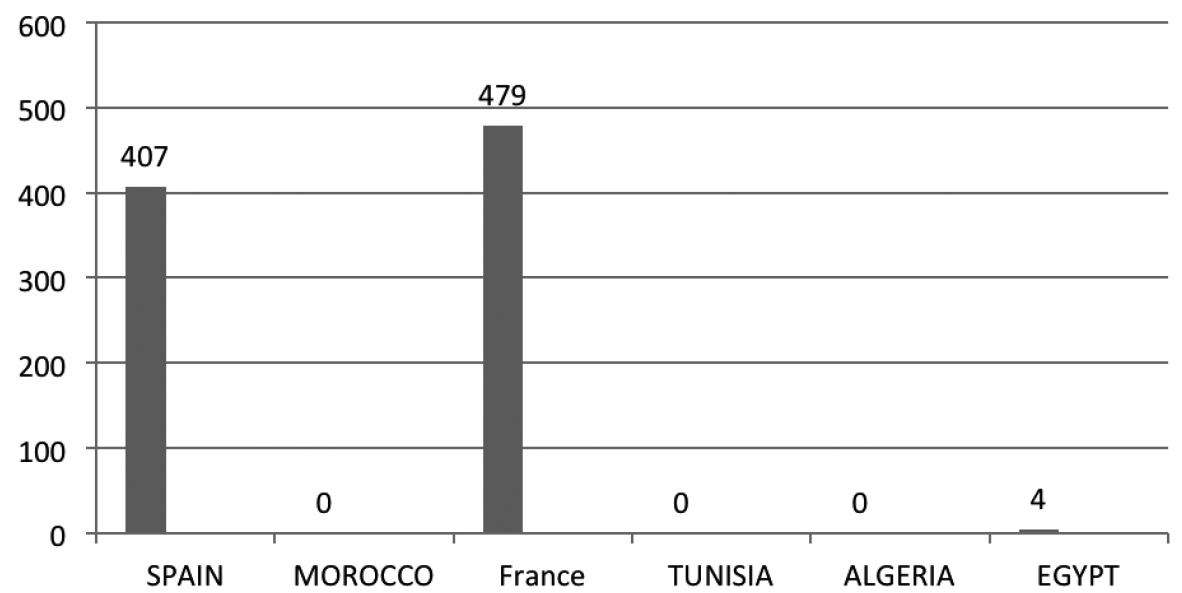

Fuente: Elaboración propia a partir de Global Reporting Initiative.

\section{Figura 5}

Comparación de la participación de las empresas marroquíes con países de su entorno 


\subsubsection{LA NORMA ISO 26000}

La Norma internacional ISO 26000, Guía sobre responsabilidad social, ofrece una guía global pertinente para las organizaciones del sector público y privado de todo tipo, basada en un consenso internacional entre expertos representantes de las principales partes interesadas, por lo que alienta la aplicación de mejores prácticas en responsabilidad social en todo el mundo. ISO 26000 contiene guías voluntarias, no requisitos, y por lo tanto no es para utilizar como una norma de certificación como la ISO 9001:2008 y la ISO 14001:2004 (ISO, 2010).

La experiencia de ISO está en el desarrollo armonizado de acuerdos internacionales basados en dobles niveles de consenso: entre las principales categorías de las partes interesadas y entre los países (ISO es una red de organismos nacionales de normalización de 163 países). De ISO 26000 se desprende una comprensión global relevante de lo que es la responsabilidad social y lo que las organizaciones tienen que hacer para operar de una manera socialmente responsable.

En este sentido, ISO 26000 ayudará a todo tipo de organización —independientemente de su tamaño, actividad o ubicación - a operar de una manera socialmente responsable, al proporcionar una guía sobre:

— conceptos, términos y definiciones relacionados con la responsabilidad social,

— antecedentes, tendencias y características de la responsabilidad social,

— principios y prácticas relativas a la responsabilidad social,

- materias fundamentales y asuntos de responsabilidad social,

- integración, implementación y promoción de un comportamiento socialmente responsable a través de toda la organización y a través de sus políticas y prácticas, dentro de su esfera de influencia,

—identificación y compromiso con las partes interesadas,

- comunicación de compromisos, desempeño y otra información relacionada con la responsabilidad social.

En el caso de Marruecos, y hasta la fecha, ninguna empresa adopta formalmente esta norma. Sin embargo, Marruecos forma parte de un proyecto piloto, llevado a cabo por la ISO y la agencia sueca del desarrollo internacional en 6 países: Argelia, Egipto, Jordania, Líbano, Marruecos y Túnez y cuyo objetivo es incitar las organizaciones del norte de África y oriente medio a adoptar y utilizar esta norma. Las empresas marroquíes que participan como empresas piloto son: Lafarge, Centrelec, Câbleries du Maroc, Holcim, Atlas Copco, Stroc, Colorado, SNEP, Maghrebsteel, Cochepa, MarocCâpres y dos establecimientos de l'OFFPPT. La figura 6 muestra la repartición de estas empresas según los países de origen. 


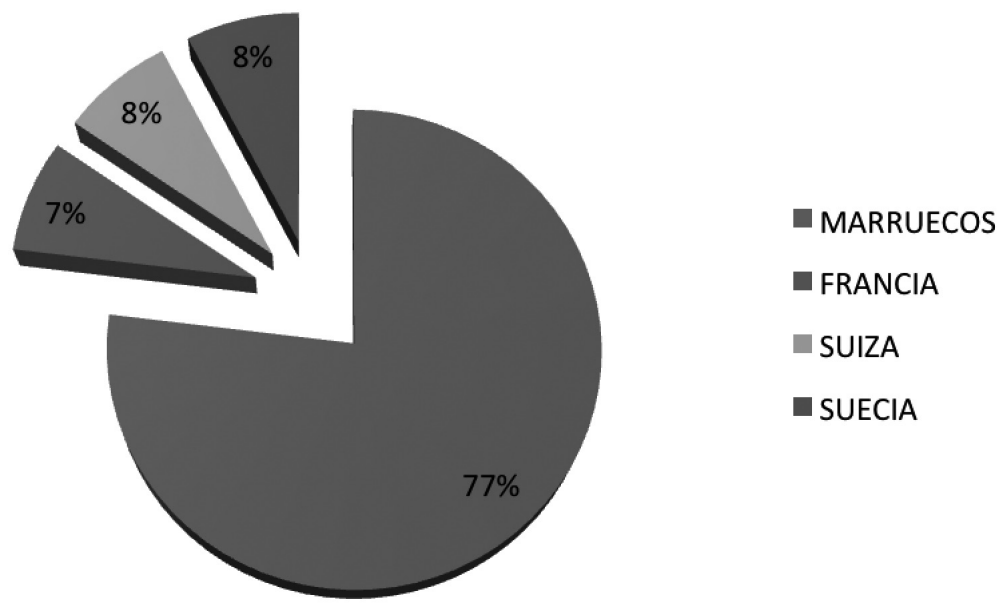

Fuente: leseco.com

Figura 6

Repartición de las empresas piloto del proyecto ISO 26000 según los países de origen (2014)

\subsection{Compromisos regionales}

\subsubsection{Política europea de Vecindad}

La Política Europea de Vecindad (PEV) se creó para impedir que aparecieran nuevas líneas divisorias entre la UE ampliada y sus países vecinos y para ofrecer a éstos la oportunidad de participar en diversas actividades de la UE a través de una mayor cooperación política, económica, cultural y de seguridad (Parlamento Europeo, 2013).

Esta ambiciosa iniciativa política, emprendida en 2003, ofrece la perspectiva de ir poco a poco más allá de las tradicionales relaciones comerciales y de cooperación para pasar a una mayor integración entre la UE y sus países vecinos. En el área económica, la PEV permite a los países vecinos intensificar sus relaciones comerciales preferenciales con la UE, participar en su mercado interior, mejorar sus conexiones con la Unión (en energía, transporte, telecomunicaciones, etc.), tener la posibilidad de participar en algunos programas de la UE y recibir una mayor asistencia financiera y técnica. En comparación con los actuales acuerdos marco entre la UE y sus países vecinos, la PEV puede catalizar mejor unas reformas estructurales y unas políticas macroeconómicas equilibradas, aunque los progresos rea- 
les seguirán dependiendo del compromiso de los propios países con la reforma.

Para el éxito de la PEV, los países vecinos participantes deberán garantizar que los compromisos contraídos en el marco de esta política refuercen sus estrategias nacionales de desarrollo y estén en consonancia con su capacidad institucional y técnica. Por su parte, la UE deberá garantizar la integridad y buen funcionamiento de su mercado interior. Los planes de acción de los países socios de la UE constituyen el núcleo de la PEV. Se trata de una serie de documentos en los que se establecen los objetivos estratégicos de la cooperación entre los países vecinos y la UE y se enumeran todas las prioridades acordadas con cada uno. Una de las grandes prioridades es fomentar el crecimiento económico mejorando las condiciones para mantener las inversiones y aumentar la productividad. Entre los demás objetivos de crecimiento de los planes de acción cabe citar los siguientes:

—alcanzar y mantener la estabilidad macroeconómica mediante políticas monetarias y fiscales prudentes,

- desarrollar el marco de los servicios financieros para mejorar el acceso a la financiación, los seguros y otros servicios financieros importantes para las empresas,

- eliminar los obstáculos administrativos, legislativos y reglamentarios a la creación y desarrollo de empresas,

- garantizar la seguridad de los derechos de propiedad, el cumplimiento de los contratos y la protección de los inversores,

- mejorar la política de competencia,

- proseguir la liberalización comercial,

- acabar con las restricciones a los movimientos de capitales,

- emprender reformas institucionales y judiciales, sobre todo para aumentar capacidades,

— respaldar la investigación y desarrollo y mejorar la calidad de la educación,

— combatir la corrupción.

Las relaciones Marruecos-UE se remontan a 1963, recibiendo un significativo impulso en la última década y, sobre todo, desde el comienzo del reinado de Mohamed VI. Marruecos encabeza la lista de socios que se beneficiaron de apoyo financiero de la Unión Europea y es pionero en la política europea de vecindad, cuyos objetivos son estrechar y fortalecer las relaciones políticas, con la celebración de una cumbre de la UE-Marruecos y el establecimiento de mecanismos de consulta a nivel ministerial; la integración del mercado único sobre la base de la adopción gradual del acervo comunitario y la cooperación sectorial; y un enfoque con clara dimensión humana. 
Los beneficios económicos potenciales de la PEV son considerables. Una mayor convergencia legislativa y reglamentaria con la UE, sobre todo en áreas importantes para mejorar el acceso al mercado, llevará a una mayor inversión y crecimiento, máxime si va acompañada de una mayor liberalización del comercio de servicios y productos agrícolas.

Según la Comisión Europea (COMMISSION EUROPÉENNE, 2014) para superar la falta de una estrategia integrada y global para el empleo y bajo la presión de las empresas y las organizaciones internacionales, el Ministerio de la familia marroquí ha anunciado recientemente el lanzamiento, en consulta con la Oficina Internacional del Trabajo, de un diagnóstico que debería conducir a una nueva estrategia nacional de empleo en 2015/2016. La UE apoyará Marruecos en el ámbito del empleo y la política social a través del programa EMPLEO-PYME (40 millones de euros), cuyo objetivo es aumentar la cantidad y mejorar la calidad de los recursos humanos que están al servicio de los sectores prioritarios de la economía marroquí.

Los objetivos de la lucha contra la pobreza y mejorar el acceso a los servicios básicos son parte de las prioridades del gobierno. Como parte de la Fase II de la Iniciativa Nacional de Desarrollo Humano (Initiative Nationale pour le Développement Humain) - INDH— (2011-2015), la UE firmó en marzo de 2013 con el gobierno de Marruecos un programa de apoyo, de 25 millones de euros con el fin de promover el desarrollo humano en sus dimensiones económicas y sociales que contribuyen a la reducción de las disparidades entre las zonas rurales y urbanas, y para fortalecer aún más la política de descentralización y la mejora de la gobernanza local.

\subsubsection{LA UNión POR EL MEditerráneO}

La Unión por el mediterráneo (UpM) es un foro de cooperación nacido el 13 de julio de 2008, durante la Cumbre de París, para promover el avance en los procesos de paz y la estabilidad en la región mediterránea. La Unión por el Mediterráneo agrupa a 43 países y más de 750 millones de ciudadanos de países ribereños del Mediterráneo y de la Unión Europea (UFM, 2014). Se fundamenta en la historia común de esta área geográfica $\mathrm{y}$, desde un punto de vista más práctico, en la cooperación en proyectos concretos de desarrollo para favorecer la integración regional. Aunque en principio sólo contemplaba la participación de los países ribereños del Mediterráneo, el plan fue modificado a instancias de Marruecos y Alemania y se incluyó a todos los Estados de la UE, como plasmación de que la política hacia el Mediterráneo es una política de toda la Unión. 
La financiación del Secretariado de la UpM procede de contribuciones de la Unión Europea y de los Estados parte. La Unión por el Mediterráneo no tiene un presupuesto con el que financiar sus proyectos, pues se concibió como un instrumento para movilizar fondos privados, de bancos de inversiones y desarrollo, y de otros organismos internacionales.

Para Marruecos el Mediterráneo siempre fue una zona estratégica y un gran área de cooperación con los vecinos euro-mediterráneos. En este contexto, la política mediterránea de Marruecos siempre se ha basado en la cooperación, la buena vecindad y apoyo a las iniciativas que puedan fortalecer la conexión entre los países del Mediterráneo. A continuación se presentan los Seis proyectos concretos que han sido seleccionadas como prioritarias para la UpM y en los cuales participa Marruecos:

— descontaminación del Mediterráneo (zonas costeras),

— creación de autopistas y modernización de las líneas ferroviarias,

— protección civil: programa conjunto sobre la prevención de catástrofes naturales y la preparación de las respuestas en el caso de producirse,

—energías alternativas: factibilidad, diseño y creación de un Plan Solar Mediterráneo,

- participación a la Iniciativa para el Desarrollo de empresas del Mediterráneo.

\subsection{Compromisos locales y certificación}

\subsubsection{LABEL CGEM}

Creada en 1947, la Confederación de Empresas de Marruecos (CGEM) es una asociación privada que agrupa los empresarios de Marruecos. CGEM representa a las empresas de todos los tamaños y todos los sectores (industria, comercio y servicios) a través del territorio, el $95 \%$ de sus miembros son pequeñas y medianas empresas. Por tanto, CGEM es un interlocutor importante de cara a las autoridades públicas y los representantes sociales.

Label CGEM para la Responsabilidad Social (RS) es un reconocimiento solemne de cumplimiento por parte de las empresas de Marruecos por su compromiso de respetar, proteger y promover los principios universales de la responsabilidad social y el desarrollo sostenible en sus actividades económicas, sus relaciones sociales y, más en general, en su contribución a la creación de valor.

A través de esta iniciativa, la CGEM promoverá la atracción de la inversión productiva y factores de crecimiento a largo plazo que son ahora, el 
desarrollo humano, el respeto de los derechos fundamentales de la persona humana y el imperio de la ley, calidad de las condiciones de empleo, la regulación de las relaciones laborales, la protección del medio ambiente, la transparencia y eficacia de las normas de competencia. A continuación se presentan los nueve compromisos de la carta de RSC (Charte de résponsabilité sociétale des entreprises):

1. respetar los derechos humanos,

2. mejorar continuamente las condiciones de trabajo y empleo y las relaciones laborales,

3. proteger el medio ambiente,

4. prevenir la corrupción,

5. respetar las normas de competencia,

6. mejorar la transparencia de la gestión empresarial,

7. respetar los intereses de los clientes y consumidores,

8. promover la responsabilidad social de los proveedores y subcontratistas,

9. desarrollar el compromiso social.

Actualmente, y según los datos comunicados por la CGEM (2014), hay 67 empresas certificadas. La figura 7 muestra la repartición de estas empresas según los países de origen.

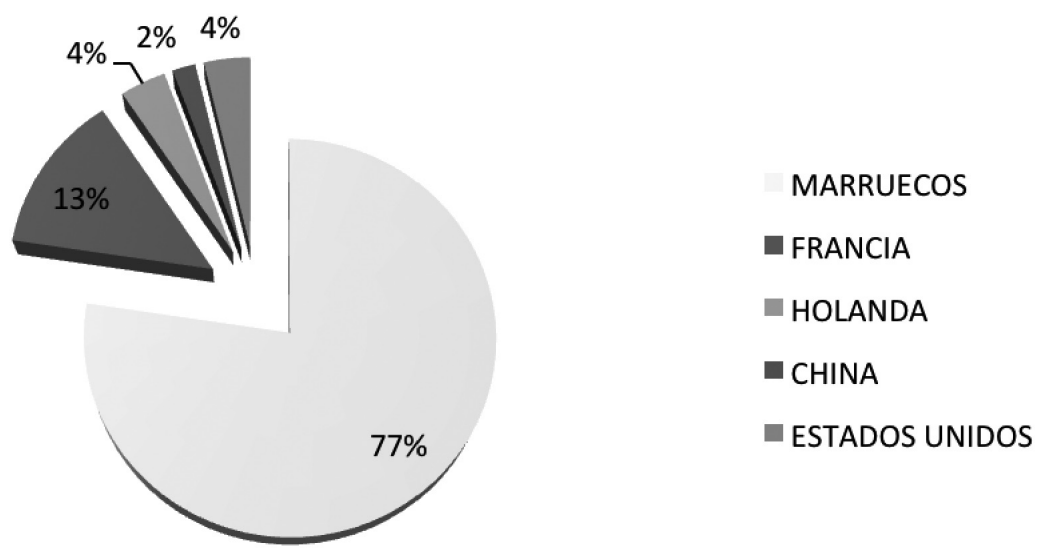

Fuente: CGEM (2014).

Figura 7

Repartición de las empresas certificadas "Label CGEM» según los países de origen (2014) 


\subsubsection{VigeO: TOP PERFORMER}

Fundado en 2002, Vigeo se ha consolidado como líder experto en análisis y evaluación ambiental, social y de gobernanza en el mercado Europeo. Vigeo incluye en su universo de evaluación numerosas empresas de todo el mundo.

Top performer es un galardón entregado por Vigeo a las empresas marroquíes que integran en su gestión objetivos medioambientales, sociales y de gobernanza en la empresa. Agrupa a las empresas que hayan acumulado en el año 2013, la puntuación más alta de los 22 criterios del referencial Vigeo, consolidados en seis áreas:

- el capital humano,

- el respeto de los derechos humanos,

- la protección del medio ambiente,

- la ética empresarial,

- la eficiencia y la independencia de la gobernanza,

- la participación comunitaria.

Las empresas de Marruecos que se llevaron este galardón en 2014, fueron: BMCE Bank, Cosumar, Lafarge Maroc, Lesieur-Cristal,Lydec, Maroc Telecom y Société métallurgique d'Imiter (SMI) (VIGEO, 2014).

\subsubsection{ONG YAMANA: LABEL «LA FIBRE CITOYENNE»}

Yamana es una ONG especializada en Responsabilidad Social Corporativa en el sector textil. Desde 1999, Yamana ha desarrollado una experiencia única en el desarrollo sostenible y la gestión de las responsabilidades sociales. Yamana aplica los principios de la norma ISO 26000 y proporciona herramientas para construir una relación de interés mutuo entre el contratista principal y los proveedores estratégicos.

Lanzado en 2005, «la fibre citoyenne», Fibra Ciudadana en español, es un programa diseñado y gestionado por Yamana y cuyo principal objetivo es acompañar a las empresas del sector textil para la integración de las cuestiones de desarrollo sostenible en el centro de sus respectivos modos de producción y de sus políticas de compra de textiles. Los principales aspectos tratados son: trabajo infantil, trabajo forzado, discriminación, higiene, salud, seguridad, remuneración y otros beneficios sociales, horarios de trabajo, libertad de asociación, subcontratación, medio ambiente y sistemas de gestión (YAMANA, 2012).

La federación del sector textil en Marruecos adopta este programa en 2007. El cuadro 4 nos muestra las 24 empresas marroquíes del sector textil certificadas en el año 2013 (Textile, 2013). 


\section{Cuadro 4}

Empresas marroquíes certificadas con «la fibre citoyenne»

\begin{tabular}{lll}
\hline \multicolumn{1}{c}{ Empresa } & $\begin{array}{c}\text { Validez } \\
\text { certificación }\end{array}$ & \multicolumn{1}{c}{ Ciudad } \\
\hline Amin Sarl & $23 / 05 / 2013$ & Rabat \\
Benjitex & $23 / 04 / 2014$ & Casablanca \\
Blue indigo sarl & $23 / 04 / 2014$ & Casablanca \\
Cindico & $23 / 05 / 2013$ & Sale \\
Cogenod & $23 / 05 / 2013$ & Tánger \\
Confection LaTulipe & $07 / 05 / 2015$ & Fes \\
Confection Salsabile & $22 / 06 / 2013$ & Tánger \\
EasternFashion & $28 / 09 / 2013$ & Guercif \\
EiremorConfection & $23 / 04 / 2014$ & Tánger \\
Formule 3 & $28 / 09 / 2013$ & Casablanca \\
J.G.R & $22 / 06 / 2013$ & Rabat \\
Larimode & $23 / 04 / 2013$ & Tánger \\
Marcotex & $28 / 09 / 2014$ & Rabat \\
Movitex & $16 / 12 / 2012$ & Casablanca \\
Mustang sarl & $23 / 04 / 2014$ & Casablanca \\
Oriental wash & $28 / 09 / 2013$ & Guercif \\
Pantex & $28 / 09 / 2014$ & Casablanca \\
Partner'sGarmentIndustry & $28 / 09 / 2013$ & Casablanca \\
Quatro Confection & $28 / 09 / 2013$ & Casablanca \\
Sinmatex & $16 / 12 / 2012$ & Berrechid \\
Souvetmaille & $16 / 12 / 2012$ & Marrekech \\
Thirteen AMP Maroc & $16 / 12 / 2012$ & Rabat \\
WOVEN MODE & $07 / 05 / 2014$ & Casablanca \\
YKK Maroc & $28 / 09 / 2014$ & Casablanca \\
\hline & & \\
\hline
\end{tabular}

Fuente: textil.ma (2014).

\section{Reflexiones y conclusiones finales}

Las buenas prácticas corporativas en los ámbitos social y medioambiental empiezan a pesar de forma importante en la toma de decisiones en las empresas de todo el mundo y, de forma más especial, en las empresas multinacionales. También las empresas de Marruecos, sean conscientes de ello o no, son sometidas a esta obligación social y medioambiental.

Como respuesta a ello, varias opciones se pueden seguir para conseguir que las actividades RSC en Marruecos no queden fuera de juego frente a 
esta nueva tendencia internacional. El dilema se encuentra en optar bien por un esquema de donaciones, por una intervención del estado o por una participación activa del sector privado.

La ayuda financiera al desarrollo de los donantes internacionales puede ser muy importante, pero por sí sola no es suficiente ni sostenible. Las iniciativas que se basan en actividades económicas son las que tienen un impacto masivo y han resultado más efectivas para ayudar a los más desfavorecidos a salir de la pobreza y evitan la dependencia de las ayudas de las agencias de cooperación. Fortalecen el tejido socioeconómico, y suelen ser más sostenibles.

En cuanto a la intervención del estado, cabe señalar que Marruecos intenta recuperar su retraso en materia de desarrollo económico a través de un cierto número de iniciativas públicas de envergadura. Pero este desarrollo económico tiene un coste y un impacto sobre el entorno natural (medio ambiente) que hay que tener en cuenta. Más aun cuando Marruecos forma parte de países signatarios de un cierto número de protocolos internacionales como el tratado de Kyoto a modo de ejemplo. De hecho, los poderes públicos, conscientes de esta situación, han puesto en marcha varios programas para proteger el medio ambiente y sacar provecho de las ventajas naturales del país en materia de energías renovables (eólicas, solares).

Otro desafío que tiene que afrontar Marruecos es la situación actual de las micro y pequeñas empresas. Los poderes públicos deberían aportar los conocimientos y destrezas necesarias para que puedan ser socios empresariales de confianza. Creemos que la puesta en marcha de modelos de desarrollo que combinan una buena gobernanza pública y privada, utilizando recursos del sector privado y su capacidad de innovación es una de las formas más efectivas de promover el desarrollo sostenible.

En muchos casos si las empresas quieren que la población esté educada, sana y con unos ingresos dignos para poder prosperar no tiene más remedio que contribuir para conseguirlo. No queremos decir con ello que cubrir las deficiencias del Estado es responsabilidad de las empresas, pero a veces se hace inevitable intervenir. Las empresas pueden conducir sus actividades de tal manera que tengan un impacto positivo en la sociedad (más allá de la aportación evidente de generación de riqueza y empleo) a la vez que pueden aumentar su rentabilidad.

\section{Referencias}

Ararat, M. (2006): «Corporate Social Responsibility across middle east and north Africa», working paper, Sabanci University, Istambul. 
BoutTi, R. (2009): «L'entreprise marocaine face à des responsabilités sociale et sociétale», Working Paper, Université Ibn Zohr, Agadir.

CGEM (2014): Liste et contacts des entreprises labellisées [disponible en http:// www.cgem.ma/upload/1282562588.pdf].

Commission Européenne (2014): Mise en æeuvre de la politique européenne de voisinage au Maroc [disponible en http://eeas.europa.eu/enp/pdf/2014/countryreports/maroc_en.pdf].

Comité Económico y Social Europeo (2014): Red de Agentes Económicos y Sociales UE-África 4 y 5 de marzo de 2014, Comité Económico y Social Europeo, Bruselas.

Cuevas, R. (2011): «Las dimensiones de la responsabilidad social de las empresas: una guía de lectura para su estudio", Revista de la Facultad de Ciencias Económicas, Universidad Militar Nueva Granada, Bogotá.

Daugareilh, I.(2009): «Responsabilidad social de las empresas transnacionales: análisis crítico y prospectiva jurídica», Cuadernos de Relaciones Laborales, 1 , pp. 77-106.

Delacampagne, M. (2013): "El grupo del Banco Africano de Desarrollo. Funcionamiento y oportunidades para empresas españolas», Boletín económico de ICE, Información Comercial Española, pp. 33-42.

El Malki, T. (2010): «Environnement des entreprises, responsabilité sociale et performance : analyse empirique dans le cas du Maroc», tesis doctoral (dir. Patricia Augier y Bouchra M'Zali), Université de la Mediterranée Aix-Marseille II.

Elósegui, M. (2010): «El Libro Verde de la RSC de la Comisión Europea y la Teoría de los Stakeholders desde una perspectiva de género», Cuadernos Electrónicos de Filosofía del Derecho, n... 21.

European Commission (2011): A renewed EU strategy 2011-14 for Corporate Social Responsibility [disponible en http://ec.europa.eu/enterprise/policies/sustainable-business/files/csr/new-csr/act_en.pdf].

Fernández, J.L., Bajo, A. (2012): «La Teoría del Stakeholder o de los Grupos de Interés, pieza clave de la RSE, del éxito empresarial y de la sostenibilidad», $A D$ Research ESIC, n... 6, pp. 130-143.

Ferre, Z.; Melgar, N.; Pastori, H.; Piani, G. y Rossi, M. (2011): «La responsabilidad social empresarial en Uruguay: una visión comparada desde la ciudadanía y desde las empresas», Semestre Económico, vol. 14, n... 30, pp. 105-120.

Fondo Monetario Internacional (FMI) (2014): Perspectives économiques regionales. Afrique subsaharienne: Pour une croissance durable et plus solidaire, Fondo Monetario Internacional, Washington.

Friedman, M. (1970): «The Social Responsibility of Business is to Increase its Profits", New York Times Magazine, September 13, 32.

Global Compact (2014): Overview of the UN Global Compact [disponible en https://www.unglobalcompact.org/AboutTheGC/index.html].

Global Compact (2015): Participant Search [disponible en https://www. unglobalcompact.org/participants/search?business_type=all\&com mit= 
Search \&cop_status=all\&country $\% 5 B \% 5 D=119 \&$ joined_after $=\&$ joined before=\&keyword =\&listing_status_id=all\&organization_type_id $=\&$ page $=1 \&$ sector_id=\&utf8=\%E2\%9C\%93].

Global Reporting Initiative (GRI) (2015): Acerca de global reporting initiative [disponible en https://www.globalreporting.org/languages/spanish/Pages/ default.aspx].

Iborra-Juan, M. y Peris-Suay, A. (2010): «Reconstruyendo la confianza en las empresas mediante la Responsabilidad Social Corporativa: Una ilustración en las cadenas de suministros del sector textil», GCG Georgetown University-Universia 2010, vol. 4, n. ${ }^{\circ} 1$.

International Monetary Fund (2014): Key indicators for Morocco [disponible en http://elibrary-data.imf.org/FindDataReports.aspx?d=33060\&e=161964] .

ISO (2010): ISO 26000 visión general del proyecto, Organización Internacional de Estandarización, Genève.

ISO (2014): ISO SUREY [disponible en http://www.iso.org/iso/home/ standards/certification/isosurvey.htm?certificate $=$ ISO $\% 2014001 \&$ countrycode=MA\#countrypick].

JimÉnez, A. (2009): «Indicadores de desempeño ambiental en el marco de la ISO 26000», Pecvnia, pp. 111-128.

Labaronne, D. y Gana-Oueslati, E.(2009): "Corporate Social Responsability, Managerial Entrenchment and Privatization», Working Paper, Université Montesquieu, Bordeaux.

Lafuente, A.; Viñuales, V.; Pueyo, R. y Llaría., J. (2003): «Responsabilidad Social Corporativa», Politicas Públicas, Fundación Alternativas.

Lesecos (2014): Des experts vulgarisent la norme de la responsabilité sociétale [disponible en http://www.leseco.ma/business/16073-des-experts-vulgarisent-lanorme-de-la-responsabilite-societale.html].

M'Hamdi, M. y Trid, S. (2009): «La responsabilité sociale de l'entreprise au Maroc: Une étude empirique auprès des petites et moyennes entreprises de la région de fès boulemane», colloque: La vulnérabilité des TPE et des PME dans un environnement mondialisé, INRPME, AUF, AIREPME, 27-29 Mai

Ministere de l'Energie, des Mines, de l'Eau et de L'Environnement (2010): Rapport de Diagnostic de l'Etat de l'Environnement au Maroc (2010), Ministère déléguée chargée de l'Environnement, Rabat, Maroc

Navarro, F. (2008): Responsabilidad Social Corporativa: Teoría y práctica, Esic editorial, Madrid.

Organización para la Cooperación y el Desarrollo Económico (OCDE) (2011): Guidelines for Multinational Enterprises, Organización para la Cooperación y el Desarrollo Económico, Paris.

Parlamento Europeo (2013): La politica europea de vecindad [disponible en http://www.europarl.europa.eu/aboutparliament/es/displayFtu. html?ftuId=FTU_6.5.4.html\#_ftn1]. 
Porter, M. y Kramer, M. (2011): «The big idea:Created shared value. How to reivent capitalism and unleash a wave of innovation and growth", Harvard Business Review, pp. 1-16.

Ruiz De Loizaga, I. (2012): «Agua, medio ambiente y pobreza en el norte de África y Oriente Medio", Boletín Económico de ICE, n. ${ }^{\circ} 3028$.

Textile (2013): Liste des entreprises labélisées FC [disponible en http://www. textile.ma/portail/PDF/Entreprises_labellisees_juin2013.pdf].

Union Africaine (2001): Nouveau partenariat pour le développement de l'Afrique [disponible en http://www.nepad.org/system/files/NEPAD\%20Framework\%20(Francais).pdf].

Union for the Meditrranean (UFM) (2014). History [disponible en http:// ufmsecretariat.org/history/].

VIGEO (2014): Vigeo désigne huit top-performers en responsabilité sociale parmi les entreprises cotées au Maroc [disponible en http://www.vigeo.com/csr-ratingagency/images/stories/Methodologie/20140106_CP_Top_performers_Maroc. pdf].

Vives, A. y Peinado-Vara, E. (2006): "RSE y desarrollo económico: Un buen negocio para todos», Compromiso empresarial, fundación compromiso y transparencia.

Yamana (2012): Fibre Citoyenne [disponible en http://www.yamana-mvd. org/?p=25]. 